\title{
8. MAGNETIC FABRIC OF QUATERNARY, TERTIARY, AND CRETACEOUS SEDIMENTS FROM THE GOBAN SPUR, LEG 80: IMPLICATIONS FOR SEDIMENT TRANSPORT PROCESSES ${ }^{1}$
}

\author{
E. A. Hailwood and S. L. Folami, Department of Oceanography, University of Southampton ${ }^{2}$
}

\begin{abstract}
Magnetic fabric data are presented for Holocene to Early Cretaceous sediments from four boreholes drilled in a transect across the western margin of the Goban Spur, west of the English Channel, during Leg 80 of the International Phase of Ocean Drilling (IPOD). Depositional magnetic fabrics have been identified in 14 samples of Holocene to late Pliocene age from Hole 548, 22 samples of late Paleocene to mid Eocene age from Hole 548A, 27 samples of Hauterivian-Barremian and Maestrichtian-Cenomanian age from Hole 549, and 13 samples of Albian-Cenomanian age from Hole 550B.

A clearly defined NE-SW or NNE-SSW grain alignment trend is evident in the magnetic fabric data for all formations studied, with the exception of the latest Paleocene to early Eocene sediments at Hole 548A. At Sites 548 and 549 this trend is approximately parallel to the local dip of the continental slope, probably as the result of the influence of downslope sediment transport processes. The trend exists in both syn-rift (Hauterivian-Barremian) and post-rift (Late Cretaceous and Tertiary) formations. It may be inferred that the mean orientation of the slope at these sites has remained essentially unchanged since the early stages of rifting and has not been modified significantly by late-rift or post-rift structural or sedimentary processes.

At Hole 548A an abrupt change from a NE-SW to a NW-SE grain alignment axis corresponds closely with a sharp unconformity in the late Paleocene. Paleomagnetic results (Townsend, this vol.) indicate that this unconformity lies in the reverse polarity interval between Anomalies 24B and 25, and on this basis it may be tentatively correlated with tectonic movements associated with the initial separation of Greenland from Rockall. Such movements probably allowed the incursion of cold bottom waters into the North Atlantic; the observed change from a NE-SW (downslope) to a NW-SE (contour-parallel) sediment transport axis at this level in Hole 548A may reflect this important change in hydrodynamic regime.
\end{abstract}

\section{INTRODUCTION}

During IPOD Leg 80 , boreholes were drilled at four sites (548 to 551) on a transect across the Goban Spur, a promontory of the northeast Atlantic margin some 250 $\mathrm{km}$ southwest of Ireland (Fig. 1). One of the main objectives of this drilling was to explore the patterns of sedimentation associated with the rifting of the margin from America in the Cretaceous and during the margin's subsequent (post-rifting) evolution. Knowledge of the changes in the patterns of sedimentation, which are inextricably linked with changes in the sources of the sediments and the sediment transport mechanisms, can assist significantly in understanding the paleoenvironmental history of the region. The purpose of the investigation described in this paper is to use analyses of the magnetic susceptibility anisotropy of the clastic sediments to provide estimates of the directions of grain alignment within them. Systematic grain alignments are normally produced by the gravitational and hydraulic forces operating on the grains during deposition. As a consequence the directions of grain alignment can be used to infer these forces, and so to provide information on the direction of transport and the source of the sediments.

\footnotetext{
${ }^{1}$ Graciansky, P. C. de, Poag, C. W., et al., Init. Repts. DSDP, 80: Washington (U.S. Govt, Printing Office).

2 Address: Department of Oceanography, The University, Highfield, Southampton, S09 $5 \mathrm{NH}$, United Kingdom.
}

\section{BACKGROUND TO MAGNETIC FABRIC METHOD}

Marine sediments deposited in an active transport regime normally possess two principal fabric elements, foliation, the gravitationally produced tendency for grains to lie with their long axes or planar surfaces within the horizontal plane, and lineation, the tendency for grain long axes within the foliation plane to be aligned along a common axis that is related to the direction of sediment transport.

This arrangement of grains applies to both the nonmagnetic and the magnetic constituents of the sediment. The alignment of the magnetic grains may be readily determined from measurements of the variation of magnetic susceptibility with direction within the sediment (i.e., from measurements of the magnetic fabric). In general, the magnetic susceptibility will have a maximum value $\left(K_{\max }\right)$ in the direction of grain long-axis alignment and a minimum value $\left(K_{\min }\right)$ perpendicular to the foliation plane (e.g., Hamilton and Rees, 1970). Thus, for a set of samples taken from a sedimentary unit that exhibits a depositional (or primary) fabric, the $K_{\min }$ axes should group close to the vertical, thereby defining a near-horizontal magnetic foliation (bedding) plane. Any grouping of $K_{\max }$ axes within this plane represents a lineation, which should be related to grain-aligning forces, such as bottom currents or downslope movements, at the time of deposition. This primary grain alignment will be disrupted, to a greater or lesser degree, in sediments that 


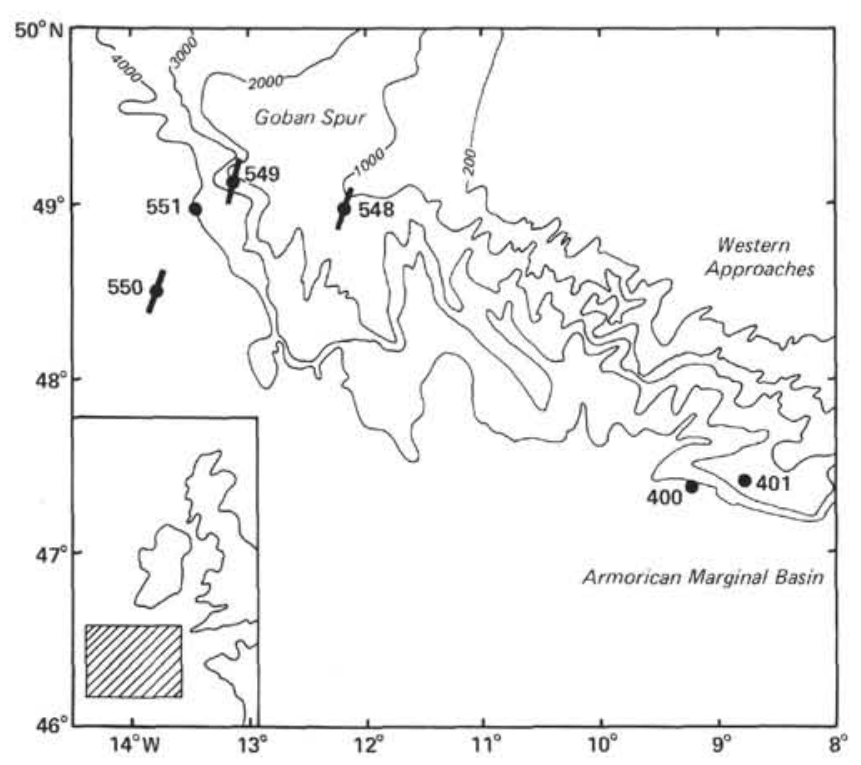

Figure 1. Location of sites referred to in this chapter. Principal grain orientation trends at Sites 548, 549, and 550 are indicated.

have undergone post-depositional disturbance as a result of bioturbation or deformation during drilling. A particular characteristic of sediments that show secondary (disturbed) fabrics is a tendency for the $K_{\min }$ axes to be displaced away from the vertical. In the present study all samples with $K_{\min }$ axes departing from the vertical by more than $20^{\circ}$ have been rejected on the grounds that their fabric may have undergone significant post-depositional modification.

Another parameter that has proved useful in identifying primary sedimentary fabrics is the azimuthal anisotropy quotient, $q$, which represents the ratio of the strength of the magnetic lineation to that of the magnetic foliation. This parameter may be calculated as follows:

$$
q=\frac{K_{\max }-K_{\mathrm{int}}}{\left(K_{\max }+K_{\mathrm{int}}\right) / 2-K_{\min }}
$$

where $K_{\max }, K_{\text {int }}$, and $K_{\min }$ represent the magnitudes of the maximum, intermediate, and minimum susceptibility axes (Rees, 1966). Laboratory flume deposition experiments indicate that the values of $q$ for undisturbed (depositional) fabrics are normally fairly uniform and are less than 0.7 , whereas the values of $q$ for sediments with fabrics that have undergone significant post-depositional modification are more erratic and are commonly greater than 0.7 . In the present study all samples with $q$ values above 0.7 were rejected on these grounds. For this investigation all susceptibility anistotropy measurements were made on a low-field torque magnetometer of the type described by King and Rees (1962), operated at an applied alternating field of $10 \mathrm{mT}$ (r.m.s.).

The geographic orientation of each sample was determined by specifying the directions of its principal susceptibility axes with respect to the direction of the stable paleomagnetic remanence; it was assumed that the latter represents a good approximation of the direction of ge- ographic north within the sample at the time of deposition (Hailwood and Sayre, 1979). Although the instantaneous geomagnetic field direction may depart by several tens of degrees from the direction of geographic (true) north, these deviations show a cyclical fluctuation with time (the secular variation), and studies of recent sediments indicate that over the course of $10^{3}$ to $10^{4} \mathrm{yr}$. the deviations average out to zero. Thus, if the time interval represented by each sample (or group of samples, if they have a common orientation) is of this order, the direction of stable paleomagnetic remanence should correspond to the direction of geographic north. Complete averaging of secular variation in the standard $2.5-\mathrm{cm}$ cylindrical samples used for this study requires that the sedimentation rate not exceed about $5 \mathrm{~m} / \mathrm{m}$.y. If the rate is significantly greater than this, errors as large as a few tens of degrees could exist in the orientation of the susceptibility axes for individual samples; however, these errors should tend to average out when groups of specimens spanning several meters of core are considered. Thus, the mean orientation of $K_{\max }$ axes with respect to the direction of stable remanence should provide a good estimate of the lineation direction with respect to geographic north at the sample site.

Theoretical considerations and laboratory experiments (e.g., Ellwood, 1979) indicate that for samples of cylindrical shape, such as those used in this study, a component of magnetic susceptibility anisotropy may result from the unequal dimensions of the sample. This shape effect may be minimized by cutting samples so that their length-to-diameter $(l / d)$ ratio lies within the optimum range from 0.84 to 0.86 . For samples with an $1 / d$ ratio significantly greater than this range, the shape effect, where present, normally manifests itself by a tendency for the $K_{\max }$ axis to become aligned close to the cylindrical axis (the $\mathrm{z}$-axis) of the sample. Because of the nature of the soft sediment samples used in the present study it was not always practicable to cut samples with optimum $l / d$ ratios. Consequently, to ensure that the overall results have not been influenced by sample shape effects, the anisotropy data for all samples with a $K_{\max }$ axis within $20^{\circ}$ of the cylinder $z$-axis have been excluded from the final analysis.

The $\mathrm{z}$-axis of the specimen always lies within the bedding plane. In cores taken by rotary drilling, the azimuths of individual core segments (and hence the z-axes of specimens taken from these segments) will tend to be randomized by differential rotations. Thus, even if a shape anisotropy is present in some samples, its effect will normally tend to be randomized. However, randomization need not necessarily occur in cores taken with the hydraulic piston corer (HPC), in which the relative azimuth of successive core sections is normally retained. By using the above rejection criterion we ran the risk of removing geologically produced systematic alignments of $K_{\max }$ axes that happened to lie close to the common $\mathrm{z}$-axis azimuth. However, the number of samples from HPC cores that was rejected by using this criterion was small ( $<10 \%$ of the total), and most of the remaining samples showed well defined $K_{\max }$ groupings. Conse- 
quently it is considered unlikely that geologically significant information was lost through this screening procedure.

\section{RESULTS OF MAGNETIC FABRIC ANALYSES}

\section{Site 548}

Two holes (548 and 548A) were drilled at Site 548, the shallowest site in the Goban Spur traverse (Fig. 1). At Hole 548, Holocene to early Pliocene sediments were cored by variable-length hydraulic piston corer to a depth of $211 \mathrm{~m}$ sub-bottom. These sediments were mainly nannofossil and marly nannofossil oozes. The degree of drilling disturbance was low, but bioturbation was fairly extensive throughout the sequence.

Rotary coring beneath this depth in Hole 548A penetrated a further $345 \mathrm{~m}$ of late Miocene to late Campanian nannofossil ooze, which overlay an Early Cretaceous or Jurassic sideritic hard ground and (at the hole's terminal depth of $551 \mathrm{~m}$ sub-bottom) Hercynian arkosic sandstones and black shales.

\section{Hole 548}

Magnetic fabric measurements were made on 50 samples from Hole 548, which spanned the entire thickness of Holocene to early Pliocene nannofossil oozes. Extensive bioturbation has led to the development of fabrics that are clearly secondary in 31 of the 50 samples. Possible shape anisotropy effects have been identified in a further 5 samples. The level of bioturbation is low or insignificant in the remaining 14 samples, which appear to have retained substantial traces of the original depositional fabric. The results are shown in the form of a stereographic projection in Figure 2A, from which it is clear that the $K_{\min }$ axes of these 14 samples are grouped close to the vertical and so define a well-developed near-hori- zontal foliation. Although the number of samples is rather small, there appears to be a tendency for the $K_{\max }$ axes to group loosely around a NE-SW trend. The southwesterly mode is clearer in Figure $2 \mathrm{~B}$, a rose diagram of $K_{\max }$ azimuths. The susceptibility axes are double ended, and the upward-directed ends of the axes are plotted in this and the other rose diagrams presented. Thus, the magnetic fabric data indicate that the preferred alignment of the long grain axes for this site is SW-NE, with an overall imbrication of the upper ends of the axes toward the SW. This trend, which is plotted on the bathymetric map in Figure 1, corresponds closely to the present-day downslope direction at the site.

Most of the samples that exhibit primary fabrics at this site are from the more terrigenous beds, which are believed to have been deposited during periods of glaciation (de Gracianski et al., this volume). The existence of a downslope grain alignment in these sediments is consistent with the view that they were deposited from turbidity currents that flowed down the continental slopes during periods when erosion and the resulting influx of sediments to the continental margin were rapid.

\section{Hole 548A}

Thirty samples from Hole 548A were subjected to magnetic fabric measurements. The samples range in age from late Paleocene to mid Eocene. Five of the 30 samples were rejected because they possessed secondary magnetic fabric characteristics, 3 more because of possible shape anisotropy effects. The anisotropy data for the remaining 22 samples are shown in Figure 3, where they are divided into three age groups (late Paleocene, early Eocene, and mid Eocene).

The $K_{\max }$ axes for the late Paleocene marly chalk and ooze samples from Core 28 fall into two groups (Fig. 3A). Those from depths below $466 \mathrm{~m}$ sub-bottom cluster

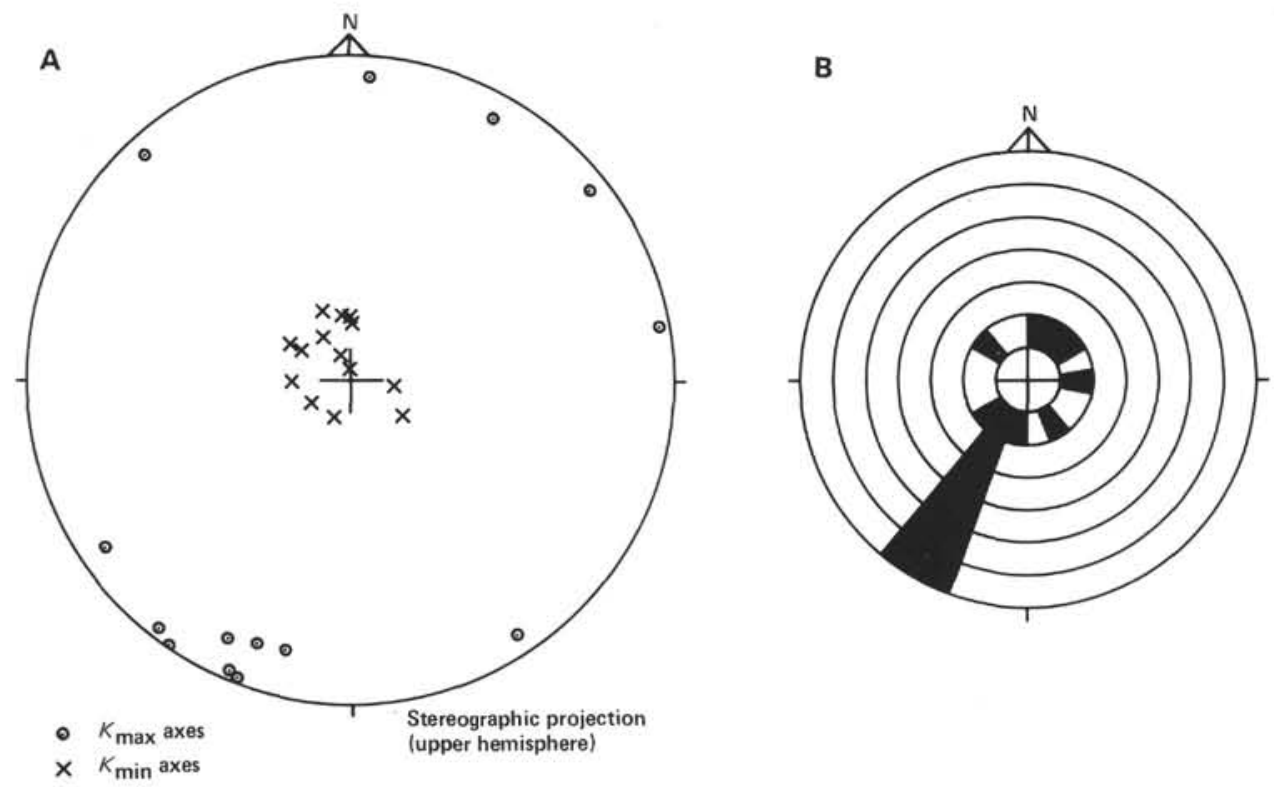

Figure 2. A. Equal-area stereographic projection of $K_{\max }$ and $K_{\min }$ axes for Holocene to late Pliocene sediments at Hole 548. B. Rose diagram showing azimuthal distribution of $K_{\max }$ axes. Shaded sectors represent numbers of points in each $20^{\circ}$ azimuthal interval (each concentric circle represents one point). In both diagrams the upward-directed ends of the susceptibility axes are plotted. 

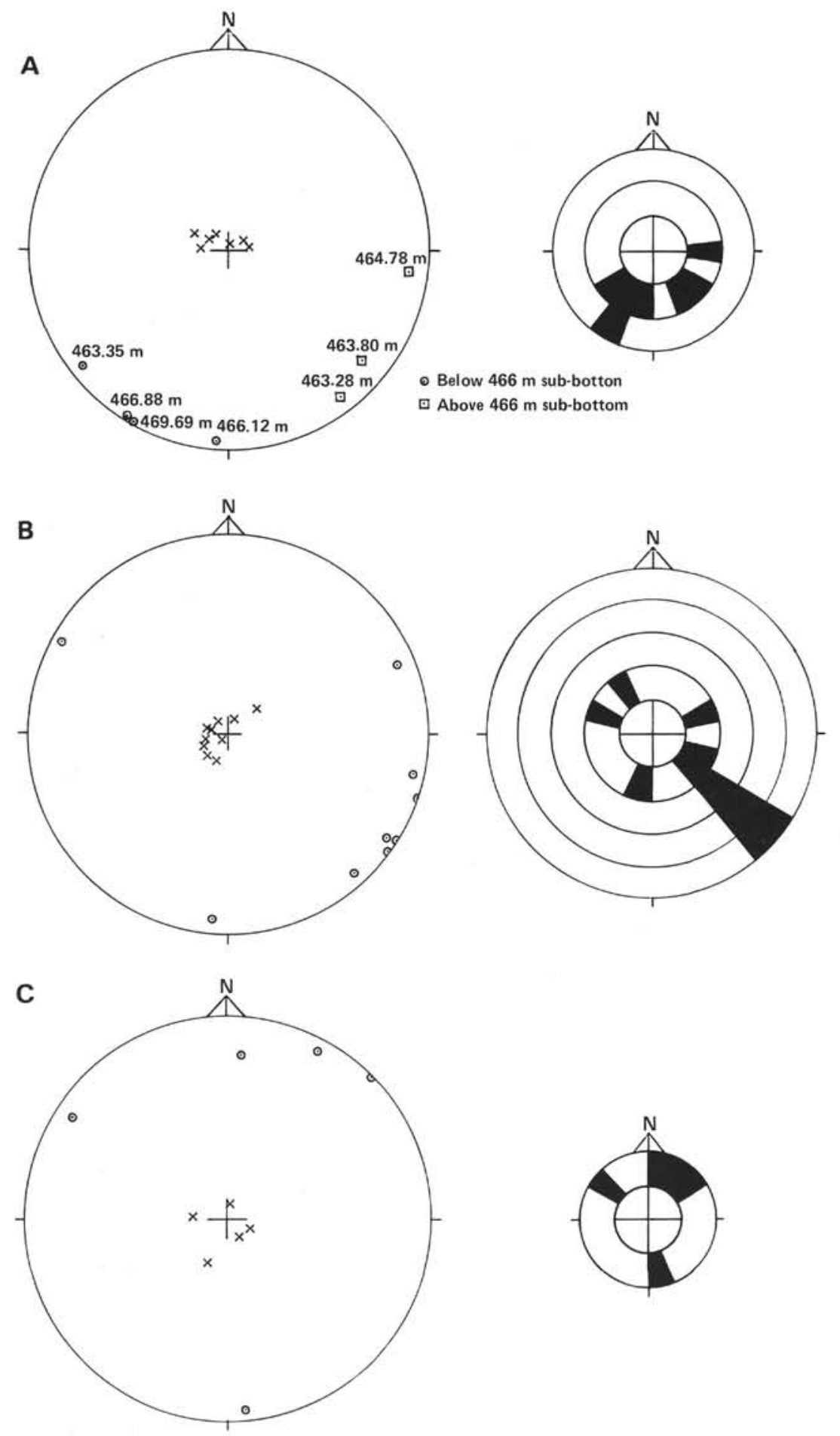

Figure 3. Stereographic projections of $K_{\max }$ and $K_{\min }$ axes, and rose diagrams showing azimuthal distribution of $K_{\max }$ axes, for Hole 548A. A. Late Paleocene marly chalk and ooze (Core 28). B. Early Eocene marly chalk and ooze (Cores 27 and 23). C. Mid Eocene nannofossil chalk (Core 22). Symbols as in Fig. 2 unless stated otherwise.

in the southwest quadrant, whereas those from above that depth group in the southeast quadrant. The SE-NW trend continues upward into the overlying early Eocene marly chalks and oozes, as evidenced by the clustering of $K_{\max }$ axes in samples of this age from Cores 27 and 23 (Fig. 3B). However, in the overlying mid Eocene nannofossil chalks, there is little trace of this axis, and instead the $K_{\max }$ axes return to a loose clustering about a NESW axis (Fig. 3C). The NE-SW trend in the oldest late Paleocene sediments appears to indicate a local downslope control on the alignment of grain long axes at this time (Fig. 1). In contrast, the NW-SE trend observed in the overlying early Eocene sediments is approximately parallel to the average orientation of bathymetric con- 
tours in this region and may reflect the influence of contour-following bottom currents. The transition from a NE-SW to a NW-SE trend appears to correspond closely with an important unconformity in the late Paleocene. Sediments at this level have been assigned to the reverse polarity interval between Anomalies 24B and 25 (Townsend, this volume), and on this basis the unconformity may be associated with the initial rifting of Greenland from the Rockall Plateau and the incursion of cold bottom waters into the North Atlantic. The sharp change in grain alignment trend at this level in Hole 548A therefore may be directly associated with the dramatic change in hydrodynamic regime that would have accompanied this event. The changes in mean grain orientation in the late Paleocene, and possibly also at the early/middle Eocene boundary correspond very closely with changes in bulk susceptibility and NRM intensity of the sediments (Townsend, this volume). Almost identical changes in the latter two parameters, particularly a marked upward decrease in their magnitude at the early/middle Eocene boundary, were observed at Sites 400 and 401 (Hailwood, 1979), some $500 \mathrm{~km}$ to the southeast of the Goban Spur (Fig. 1). Since both parameters are sensitive to the amount of detrital magnetite in the sediments, it is concluded that a significant rise in input of this material (probably from volcanic sources) to the whole area occurred in the late Paleocene, at the time of the change from a NE-SW to a NW-SE transport axis. This relatively high input of volcanically derived terrigenous material continued throughout the early Eocene while the NW-SE transport process dominated but ended abruptly at the early/mid Eocene boundary, at the same time as the possible return to a NE-SW trend.

\section{Site 549}

Site 549 is located near the seaward end of a tilted fault block on the western margin of the Goban Spur, some $70 \mathrm{~km}$ west of Site 548 (Fig. 1). A 1-km-thick sequence of Tertiary and Cretaceous chalks, mudstones, sandstones, and limestones overlying Paleozoic foliated micaceous sandstones was penetrated. Magnetic fabric analyses were restricted to the Cretaceous sediments at this site, and in total 81 samples were measured. These samples fall into two distinct age groups: Maestrichtian to Cenomanian (Cores 22-28) and Barremian to Hauterivian (Cores 61-93). The Barremian-Hauterivian sediments are represented mainly by calcareous and sandy mudstones that are thought to represent syn-rift deposits that accumulated rapidly during the transgression of marine waters over an upraised basement block (de Gracianski et al., this volume). The younger MaestrichtianCenomanian deposits are mainly light-colored greenish gray nannofossil chalks that are believed to have been deposited during the rapid subsidence of the Goban Spur and the rise in sea level that followed the lower Cenomanian sea level drop.

Parts of both of these intervals have undergone drilling disturbance, the effects of which are not always visible to the naked eye but are clearly detected by the diagnostic magnetic fabric parameters. Of 25 samples from the Maestrichtian-Cenomanian chalks and 56 from the
Barremian-Hauterivian mudstones, 9 and 32 samples respectively had fabrics affected by deformation. Thirteen other samples from the two formations were rejected because of possible shape anisotropy effects. The magnetic fabric data for the remaining 9 Maestrichtian-Cenomanian and 18 Barremian-Hauterivian samples are summarized in Figure 4.

For both sets of samples the $K_{\max }$ axes show distinct groupings in the first and third quadrants, from which a clearly developed NNE-SSW grain alignment may be deduced. When plotted on the bathymetric map (Fig. 1), this lineation is clearly perpendicular to the continental margin at Site 549.

The similarity between the mean grain orientation directions in the two groups of samples is striking, the more so because of the differences in their presumed depositional environments. The simplest view is that the same structural lineaments that control the present-day WNW-ESE strike of the continental slope at this site affected the orientation of the slope during both the Hauterivian-Barremian syn-rift phase and the subsequent Maestrichtian-Cenomanian sea level rise. The implication is that post-rift processes have caused no major changes in local slope orientation and that the dominant sediment transport process at this site was downslope movement rather than contour current activity throughout the Cretaceous.

\section{Site $\mathbf{5 5 0}$}

Site 550 is at a water depth of $4430 \mathrm{~m}$ and is located on the abyssal plain about $10 \mathrm{~km}$ southwest of the seaward edge of the Goban Spur. A sequence of Tertiary nannofossil oozes, chalks, and mudstones, overlying Cretaceous (late Albian to Maestrichtian) nannofossil chalks, mudstones, and shales was cored. Magnetic anisotropy measurements were carried out on the sequence of interbedded calcareous mudstones and black shales of mid Cenomanian to late Albian age recovered from Hole $550 \mathrm{~B}$. This lithologic unit overlies basalts with thin intercalated layers of late Albian sediments, and it is separated from the overlying unit of Santonian-Coniacian mudstones by an important hiatus.

An attempt was made to confine the sampling to the nonbioturbated mudstone layers, and consequently the proportion of samples that show secondary fabrics is small. Only 3 of a total of 16 samples show traces of deformational characteristics. The maximum and minimum susceptibilty axes for the remaining 13 samples are plotted in Figure 5. Although some scatter is evident, the rose diagram of $K_{\max }$ azimuths shows a clearly developed NNE-SSW trend.

\section{DISCUSSION}

After rigid rejection criteria were applied to eliminate samples in which the fabric may have been modified by drilling or bioturbation, the systematic grain alignment trends in each of the groups of sediments studied from Sites 548, 549, and 550 were identified. With the exception of the late Paleocene-early Eocene sediments in Hole $548 \mathrm{~A}$, the mean grain orientation in all formations studied was aligned approximately NNE-SSW. 

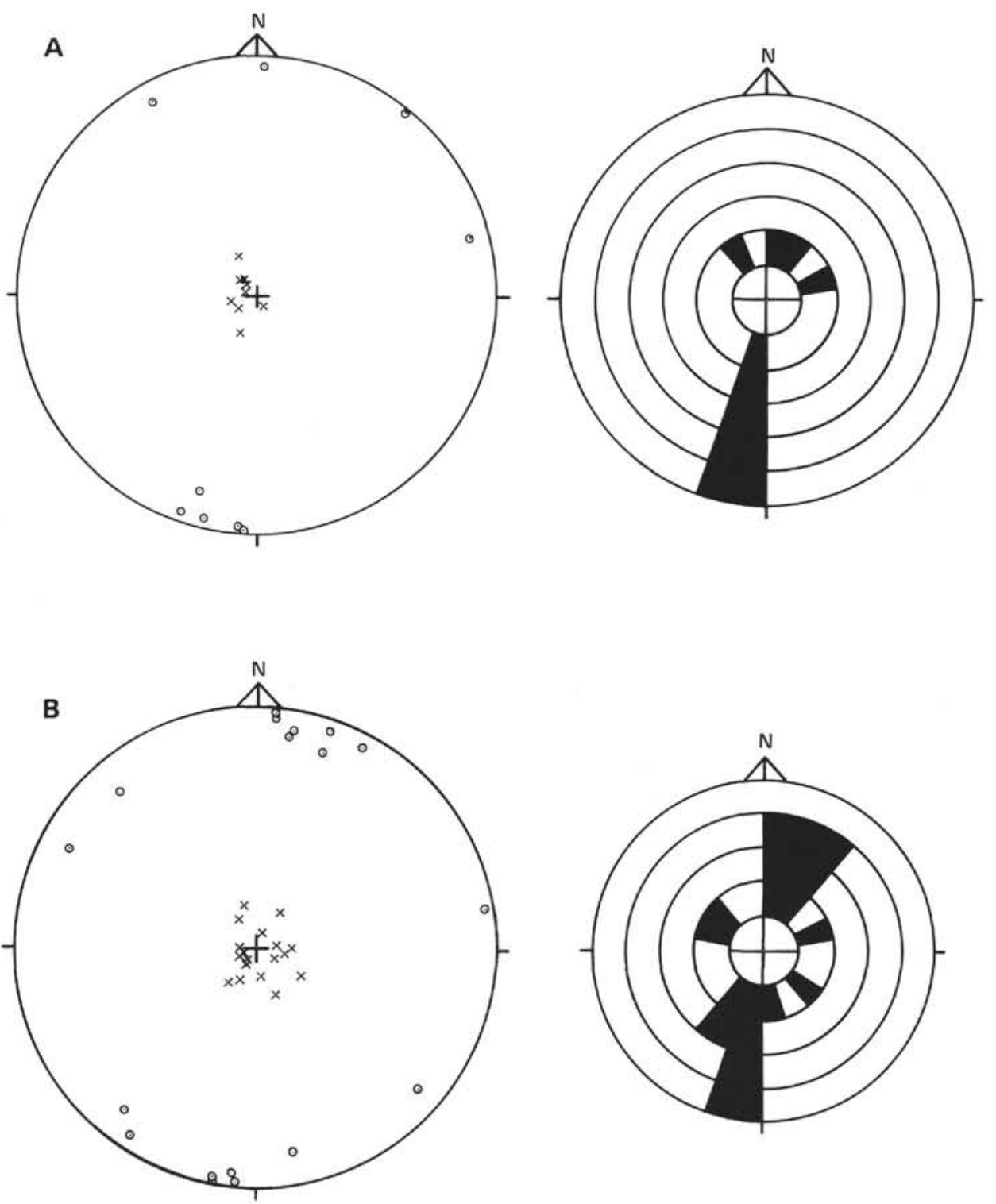

Figure 4. Stereographic projections of $K_{\max }$ and $K_{\min }$ axes, and rose diagrams showing azimuthal distribution of $K_{\max }$ axes, for Hole 549. A. Maestrichtian to Cenomanian sediments (Cores 2228). B. Barremian-Hauterivian sediments (Cores 61-93). Symbols as in Fig. 2.

If the sediments at these sites were deposited in the presence of an active bottom current, the grain alignment would be expected to be influenced by the fluid flow. Laboratory experiments (e.g., Hamilton and Rees, 1970 ) indicate that for a wide range of current velocities the mean grain orientation tends to be closely parallel to the current velocity vector. One interpretation of these data therefore is that the whole of the Goban Spur region has been influenced by a dominant NNE-SSW bottom flow regime from the Early Cretaceous to the present time. However, it is hard to believe that such a process continued throughout the various stages of evolution of the margin.

The grain alignment direction, when examined in more detail, is clearly perpendicular to the local strike of the continental slope at Sites 548 and 549, and therefore it seems more likely that the grain orientation is either a direct result of active downslope transport or the result of the gravitational pull exerted on grains deposited on a slope (Rees, 1966). In either case it may be concluded that the orientation of the continental slope has remained essentially unchanged from the early stages of rifting to the present, despite the post-rift deposition of thick sequences of sediments in this region.

An exception to the overall NNE-SSW trend is the NW-SE grain alignment in the late Paleocene and early Eocene marly chalks and oozes at Hole 548A. This change to a cross-slope trend appears to occur quite abruptly at the level of the late Paleocene unconformity in Core 28 (Fig. 3A). A possible return to a downslope trend has been tentatively identified at the early/mid Eocene boundary, between Cores 23 and 22. An expla- 


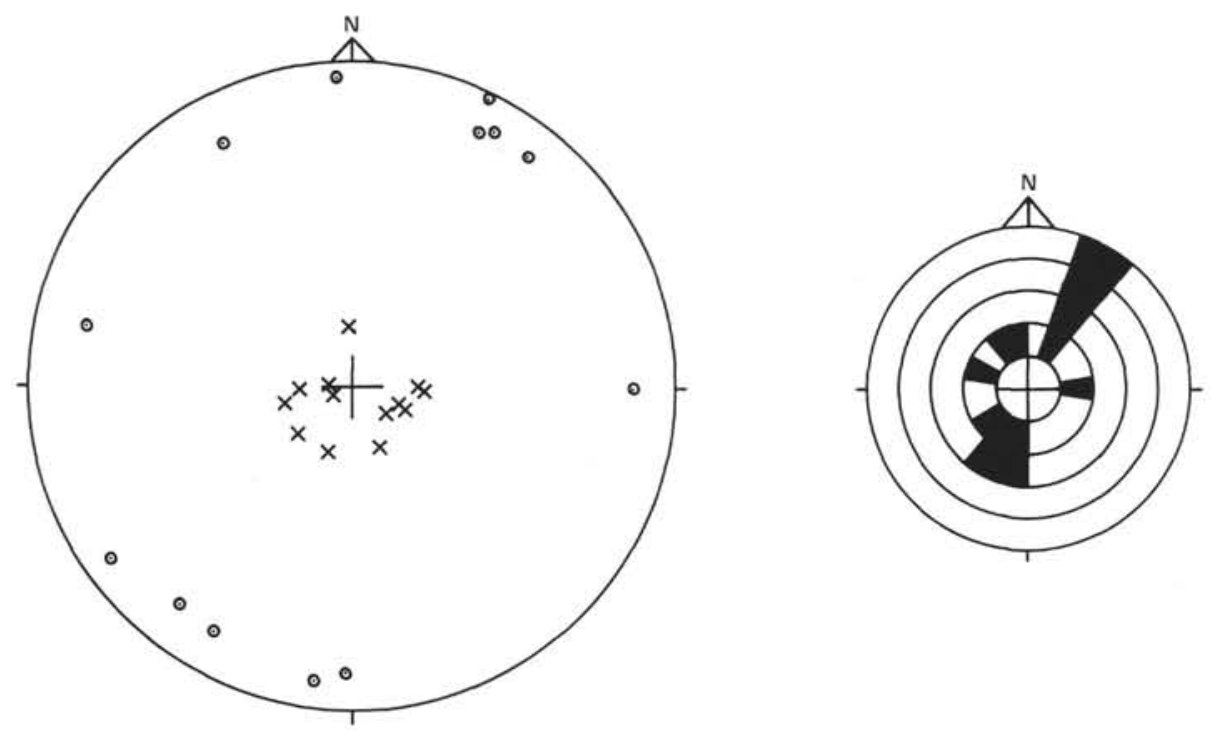

Figure 5. Stereographic projection of $K_{\max }$ and $K_{\min }$ axes, and rose diagram showing azimuthal distribution of $K_{\max }$ axes, for Albian to Cenomanian sediments at Hole 550B (Cores 21-25). Symbols as in Fig. 2 .

nation for this change to a cross-slope trend is an episode of contour current activity in the region at the end of the Paleocene, which was possibly associated with the opening of the northeast Atlantic and the incursion of cold bottom waters into the North Atlantic at this time. As remarked above, this episode appears to coincide closely in time with a marked increase in the bulk susceptibility and the NRM intensity of the sediment, which is thought to reflect an increase in the proportion of volcanically derived material.

These changes are of considerable paleoceanographic interest; further detailed study of the early Paleogene sedimentary sequences on the northeast Atlantic margin is clearly warranted.

\section{ACKNOWLEDGMENTS}

We are very grateful to Georgina Allan for assistance with measurements and for drafting the diagrams, and to Jean Watson for typing the manuscript. We thank Hilary Townsend for helpful discussions, and for providing paleomagnetic orientation information. The manuscript benefited from helpful reviews by Norman Hamilton, PierreCharles de Graciansky, and David G. Roberts. Financial support for Samuel Folami from the University of Ife is gratefully acknowledged.

\section{REFERENCES}

Ellwood, 2. B., 1979. Sample shape and magnetic grain sizes: two possible cintrols on the anisotropy of magnetic susceptibility variability in deep-sea sediments. Earth Planet. Sci. Lett., 43:309-314.

Hailwood, E. A., 1979. Paleomagnetism of late Mesozoic to Holocene sediments from the Bay of Biscay and Rockall Plateau, drilled on IPOD Leg 48. In Montadert, L., Roberts, D. G., et al., Init. Repts. DSDP, 48: Washington (U.S. Govt. Printing Office), 305-339.

Hailwood, E. A., and Sayre, W. O., 1979. Magnetic anisotropy and sediment transport directions in North Atlantic Early Cretaceous black shales and Eocene mudstones cored on DSDP Leg 48. In Montadert, L., Roberts, D. G., et al., Init. Repts. DSDP, 48: Washington (U.S. Govt. Printing Office), 909-918.

Hamilton, N., and Rees, A. I., 1970. The use of magnetic fabric in palaeocurrent estimation. In Runcorn, S. K. (Ed.), Palaeogeophysics: New York (Academic Press), pp. 445-464.

King, R. F., and Rees, A. I., 1962. The measurement of the anisotropy of magnetic susceptibility of rocks by the torque method. J. Geophys. Res., 67:1565-1572.

Rees, A. I., 1966. The effect of depositional slopes on the anistropy of magnetic susceptibility of laboratory deposited sands. J. Geol., 74: 856-867.

Date of Initial Receipt: December 3, 1982

Date of Acceptance: July 22, 1983 